\title{
Cytokine adsorption in patients with severe COVID-19 pneumonia requiring extracorporeal membrane oxygenation
}

\author{
Marina Rieder ${ }^{1,2}$, Tobias Wengenmayer ${ }^{1,2}$, Dawid Staudacher ${ }^{1,2}$, Daniel Duerschmied ${ }^{1,2}$ and Alexander Supady ${ }^{1,2^{*}}$ (D)
}

The treatment of patients with severe COVID-19 requiring support with veno-venous extracorporeal membrane oxygenation (vv-ECMO) is particularly challenging from a medical point of view and consumes a tremendous amount of human, physical, and financial resources. Recommendations for initiation of vv-ECMO in COVID-19 are being developed, though under continuous review $[1,2]$. However, despite all therapeutic efforts, these critically ill patients have a high mortality rate according to studies published so far $[3,4]$.

At our hospital, a major referral center for extracorporeal support, we have treated several COVID19 patients with vv-ECMO. Knowing interleukin-6 (IL-6) as a predictor of negative outcome, some patients received cytokine adsorption using the CytoSorb $^{\circ}$ adsorber (CytoSorbents Europe, Berlin, Germany) shortly after initiation of ECMO for up to $72 \mathrm{~h}$ [5]. Based on experience in septic patients, the adsorber was exchanged every $24 \mathrm{~h}$ [6]. Integration of the adsorber in the ECMO circuit was feasible and safe. Preliminary data from eight cases (4 patients receiving ECMO with cytokine adsorption, the remaining 4 received ECMO without cytokine adsorption) shows that cytokine adsorption may result in a more pronounced decrease of IL- 6 after initiation of ECMO (Fig. 1).

Whether this observation can be confirmed in larger cohorts and the degree to which this effect is caused by the adsorber instead of just being a sign of general clinical improvement warrants further investigation.
Finally, whether this translates into improved clinical outcome remains to be shown, either.

Therefore, we set up a clinical trial to further examine this preliminary observation. The CYCOV-II study (cytokine adsorption in patients with severe COVID-19 pneumonia requiring extracorporeal membrane oxygenation) is a randomized, controlled, open-label intervention, multicenter trial comparing cytokine adsorption in ECMO treatment for COVID-19 with a control group receiving standard ECMO treatment without cytokine adsorption (Fig. 2; NCT04385771).

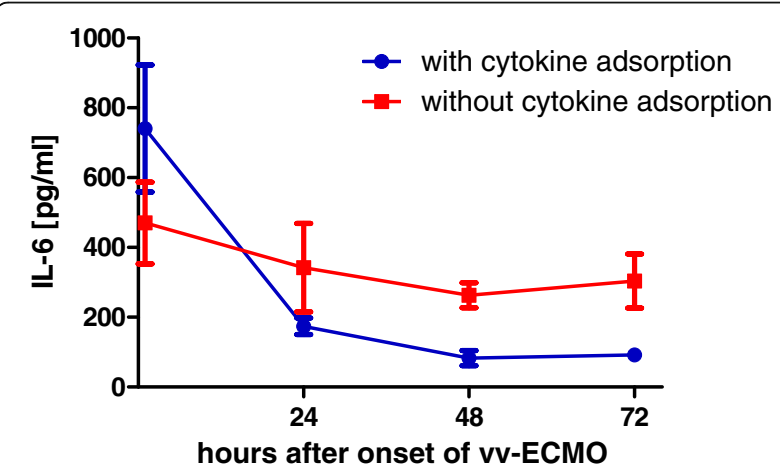

Fig. $1 \mathrm{IL}-6$ levels within the first $72 \mathrm{~h}$ after onset of $\mathrm{Vv}-\mathrm{ECMO}$ in 8 patients. Four patients received $\mathrm{v} v-\mathrm{ECMO}$ without cytokine adsorption (red), and 4 patients $v v-E C M O$ with cytokine adsorption (blue). Data are presented as mean \pm SEM

\footnotetext{
* Correspondence: alexander.supady@universitaets-herzzentrum.de 'Department of Medicine III (Interdisciplinary Medical Intensive Care), Medical Center, Faculty of Medicine, University of Freiburg, Freiburg, Germany ${ }^{2}$ Department of Cardiology and Angiology I, Heart Center, University of Freiburg, Hugstetter Strasse 55, 79106 Freiburg, Germany
} 


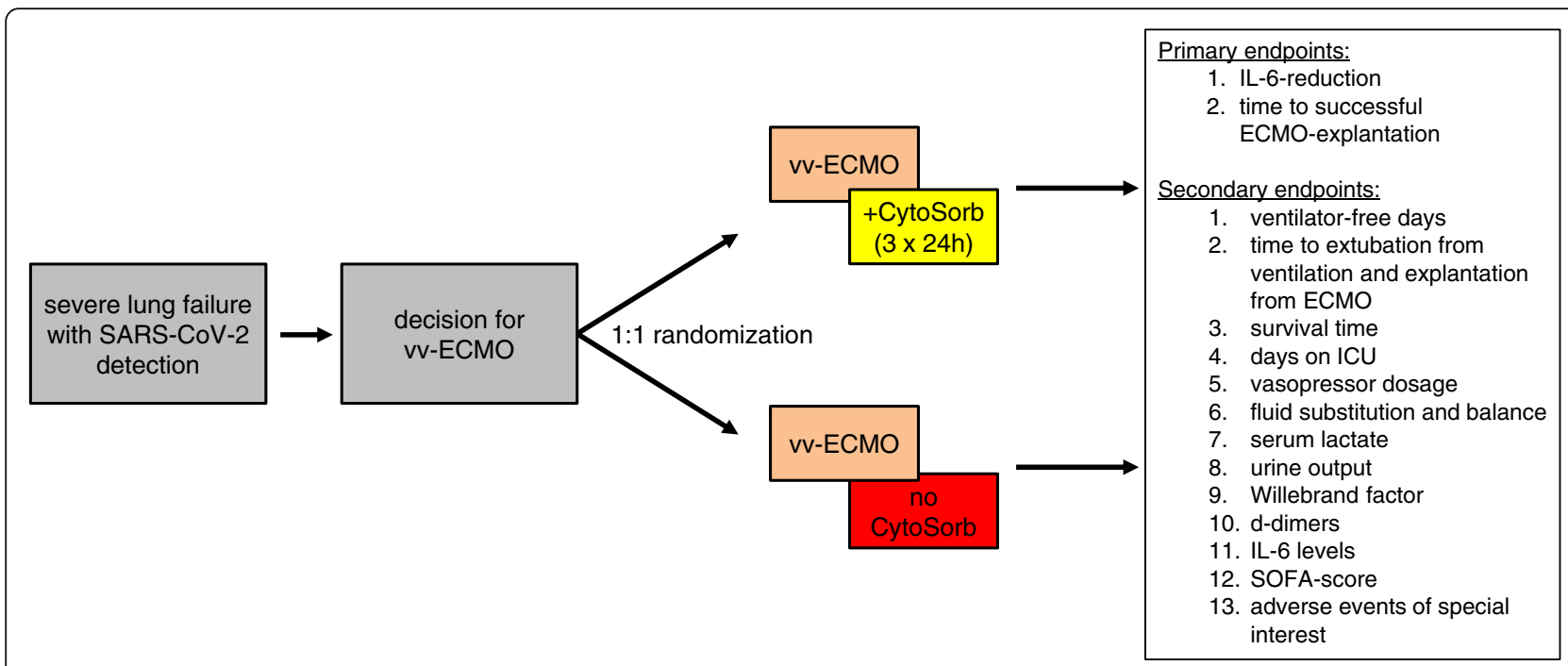

Fig. 2 Graphic representation of the study design for the CYCOV-II trial

In all participating centers, we plan to randomize all COVID-19 patients receiving vv-ECMO into the study groups. Cytokine adsorption will be performed for $72 \mathrm{~h}$. The primary endpoints of the study are (1) IL-6 reduction by $75 \%$ or more after $72 \mathrm{~h}$ as compared to the baseline measurement and (2) time to successful ECMO explantation within 30 days after randomization. Further clinically relevant endpoints, such as ventilator free days, days on intensive care unit, and overall survival time, will be assessed as secondary endpoints.

With this study, we expect to clarify whether cytokine adsorption is beneficial in severely affected COVID-19 patients requiring vv-ECMO support.

\section{Acknowledgements}

None.

\section{Authors' contributions}

A Supady and D Duerschmied designed the study. The data collection and evaluation were conducted by M Rieder and A Supady. T Wengenmayer and D Staudacher supported in the study design, data collection, and evaluation. M Rieder and A Supady wrote the first draft of the manuscript. The author(s) read and approved the final manuscript.

\section{Funding}

This work was financed by internal funds from the participating institutions.

Availability of data and materials

All data will be available from the corresponding author on reasonable request.

\section{Ethics approval and consent to participate}

Data collection was approved by the institutional ethics committee of the University of Freiburg (EK 168/20), and informed consent was obtained from all participants or legal representatives.

\section{Competing interests}

Alexander Supady and Daniel Duerschmied received speakers' honoraria from CytoSorbents, the manufacturer of the CytoSorb device. The

Department of Cardiology and Angiology I received a research grant from CytoSorbents.

Received: 2 June 2020 Accepted: 1 July 2020

Published online: 14 July 2020

\section{References}

1. Rajagopal K, Keller SP, Akkanti B, Bime C, Loyalka P, Cheema FH, Zwischenberger JB, El Banayosy A, Pappalardo F, Slaughter MS, et al. Advanced pulmonary and cardiac support of COVID-19 patients: emerging recommendations from ASAIO-A "living working document". ASAIO J. 2020; 66(6):588-98.

2. Shekar K, Badulak J, Peek G, Boeken U, Dalton HJ, Arora L, Zakhary B, Ramanathan K, Starr J, Akkanti B, et al. Extracorporeal life support organization COVID-19 interim guidelines. ASAIO J. 2020. Online ahead of print.

3. Cummings MJ, Baldwin MR, Abrams D, Jacobson SD, Meyer BJ, Balough EM, Aaron JG, Claassen J, Rabbani LE, Jonathan $\mathrm{H}$ et al: Epidemiology, clinical course, and outcomes of critically ill adults with COVID-19 in New York City: a prospective cohort study. Lancet. 2020;395(10239):1763-70.

4. Henry BM, Lippi G. Poor survival with extracorporeal membrane oxygenation in acute respiratory distress syndrome (ARDS) due to coronavirus disease 2019 (COVID-19): pooled analysis of early reports. J Crit Care. 2020:58:27-8.

5. Ruan $\mathrm{Q}$, Yang K, Wang W, Jiang L, Song J: Clinical predictors of mortality due to COVID-19 based on an analysis of data of 150 patients from Wuhan China. Intensive Care Med. 2020;46(5):846-8.

6. Kogelmann K, Jarczak D, Scheller M, Druner M. Hemoadsorption by CytoSorb in septic patients: a case series. Crit Care. 2017;21(1):74.

\section{Publisher's Note}

Springer Nature remains neutral with regard to jurisdictional claims in published maps and institutional affiliations.

\section{Consent for publication}

Not applicable. 